\title{
The effect of automated oxygen control on clinical outcomes in preterm infants: a pre- and post-implementation cohort study
}

\author{
H. H. Salverda ${ }^{1}$ (D) - N. J. Oldenburger ${ }^{1}$ - M. Rijken ${ }^{1}$ - S. C. Pauws ${ }^{1,2} \cdot$ P. A. Dargaville ${ }^{3,4} \cdot$ A. B. te Pas ${ }^{1}$
}

Received: 20 October 2020 / Revised: 10 January 2021 / Accepted: 4 February 2021 / Published online: 23 February 2021

(C) The Author(s) 2021

\begin{abstract}
Several studies demonstrated an increase in time spent within target range when automated oxygen control (AOC) is used. However the effect on clinical outcome remains unclear. We compared clinical outcomes of preterm infants born before and after implementation of AOC as standard of care. In a retrospective pre-post implementation cohort study of outcomes for infants of 24-29 weeks gestational age receiving respiratory support before (2012-2015) and after (2015-2018) implementation of AOC as standard of care were compared. Outcomes of interest were mortality and complications of prematurity, number of ventilation days, and length of stay in the Neonatal Intensive Care Unit (NICU). A total of 588 infants were included (293 pre- vs 295 in the post-implementation cohort), with similar gestational age (27.8 weeks pre- vs 27.6 weeks post-implementation), birth weight (1033 grams vs 1035 grams) and other baseline characteristics. Mortality and rate of prematurity complications were not different between the groups. Length of stay in NICU was not different, but duration of invasive ventilation was shorter in infants who received AOC $(6.4 \pm 10.1$ vs $4.7 \pm 8.3, p=0.029)$.

Conclusion: In this pre-post comparison, the implementation of AOC did not lead to a change in mortality or morbidity during admission.

What is Known:

- Prolonged and intermittent oxygen saturation deviations are associated with mortality and prematurity-related morbidities.

- Automated oxygen controllers can increase the time spent within oxygen saturation target range.

What is New:

- Implementation of automated oxygen control as standard of care did not lead to a change in mortality or morbidity during admission.

- In the period after implementation of automated oxygen control, there was a shift toward more non-invasive ventilation.
\end{abstract}

Keywords Hypoxemia $\cdot$ Hyperoxia $\cdot$ Closed loop $\cdot$ Algorithm $\cdot$ Neonate $\cdot$ Respiratory

Communicated by Daniele De Luca

H. H. Salverda

H.H.Salverda@lumc.nl

1 Division of Neonatology, Department of Paediatrics, Leiden University Medical Center, PO box 9600, 2300

RC Leiden, The Netherlands

2 TiCC, Tilburg University, Tilburg, The Netherlands

3 Paediatrics, Royal Hobart Hospital, Hobart, Tasmania, Australia

4 Menzies Institute for Medical Research, University of Tasmania, Hobart, Tasmania, Australia

\section{Introduction}

Preterm infants born under 30 weeks of gestation spend a long period in the neonatal intensive care unit (NICU), where they experience considerable morbidities during and after their admittance [1]. Often they receive respiratory support which includes supplemental oxygen, administered with the aim of keeping oxygen saturation $\left(\mathrm{SpO}_{2}\right)$ within a prescribed target range (TR) and preventing hypoxia and hyperoxia. Both frequent and prolonged $\mathrm{SpO}_{2}$ deviations have been associated with mortality and prematurity-related morbidities, including retinopathy of prematurity (ROP), periventricular leukomalacia (PVL), necrotising enterocolitis (NEC), bronchopulmonary dysplasia (BPD), and neuro-developmental impairment [2-5]. 
Titrating the fraction of inspired oxygen $\left(\mathrm{FiO}_{2}\right)$ to keep $\mathrm{SpO}_{2}$ within the TR has proved challenging. Several studies have reported on the difficulty of $\mathrm{SpO}_{2}$ targeting when $\mathrm{FiO}_{2}$ is titrated manually, reflected in a proportion of $\mathrm{SpO}_{2}$ TR time of around $50 \%$ or less. Lack of knowledge and a high workload for the caregivers were described as important factors for low compliance [6-9]. Continuous oxygen titration by an automated oxygen control (AOC) device aims to circumvent these problems and improve $\mathrm{SpO}_{2}$ targeting whilst reducing the bedside workload. During AOC, signals from a pulse oximeter are continuously input to a computer algorithm which determines what adjustments to $\mathrm{FiO}_{2}$ are necessary based on the oxygenation feedback [10]. The changes to $\mathrm{FiO}_{2}$ are actuated automatically within a ventilator or other respiratory support device. Studies investigating the effect of AOC on oxygen saturation over 24-h periods have demonstrated a beneficial effect, with infants spending more time within TR, accompanied by a decrease of severe hypoxia and hyperoxia [11-18].

AOC was implemented as standard care in the Neonatal Intensive Care Unit (NICU) of the Leiden University Medical Center (LUMC) in August 2015. We recently reported the effect of this implementation on oxygen saturation in preterm infants during admission [15]. Infants spent more time within TR and less time with $\mathrm{SpO}_{2}>95 \%$, but a lesser effect on duration of $\mathrm{SpO}_{2}<80 \%$. Thus far, none of the studies comparing manual oxygen control with AOC have reported the effect on clinical outcomes. We therefore aimed to assess the effect of implementation of AOC as standard care on outcomes in preterm infants during their hospital admission.

\section{Materials and methods}

\section{Study design}

A retrospective observational study was performed in the NICU of the Leiden University Medical Center (LUMC). This is a tertiary-level perinatal centre with an average of 100 intensive care admissions per year of infants born before 30 weeks of gestation. The ethical board of the LUMC provided a statement of no objection for obtaining and publishing the anonymised data.

Infants born from $24+0$ until $29+6$ weeks of gestation and admitted to the NICU between May 1, 2012, and December 31, 2018, were included in the study. Infants were excluded from the analysis if admitted $>24 \mathrm{~h}$ after birth, had major congenital abnormalities or required no invasive or noninvasive respiratory support during their admission.

The pre-implementation cohort consisted of infants admitted between May $1^{\text {st }} 2012$ and June $17^{\text {th }} 2015$ who received manual $\mathrm{FiO}_{2}$ titration from bedside staff according to local guidelines. The post-implementation cohort was composed of infants admitted from October $18^{\text {th }} 2015$ to December 2018, allowing for a washout period of 4 months.

\section{Data collection}

All data are retrieved from our patient data management system (Metavision; IMDsoft, Tel Aviv, Israel). The following outcomes were noted: mortality, ROP, BPD, NEC, culture proven sepsis, intraventricular haemorrhage (IVH), PVL, and length of NICU stay. The duration of respiratory therapy and supplemental oxygen (measured fraction of inspiratory oxygen above 0.21 ) was calculated from our patient data management system which routinely samples clinical parameters and ventilator settings once per minute. Mortality until 1 month after corrected term age was noted. The ophthalmologists in our hospital implemented the Early Treatment of Retinopathy of Prematurity study (ETROP) classification for findings of retinal examination in 2013, and ROP was defined according to this classification $[19,20]$. When retinal findings were described otherwise, researcher NJO classified according to the ETROP criteria retrospectively, assisted by an ophthalmologist where necessary. An assessment for BPD was made at 36 weeks postmenstrual age, using where necessary discharge papers from regional hospitals and classified as mild, moderate, or severe according to criteria from the 2000NICHD consensus. [21] NEC was defined according to the modified Bell staging criteria.[22] IVH was classified according to Papile's adapted classification [23, 24], PVL according to the de Vries' classification. [25]

\section{Oxygen titration}

Following the recent European guidelines [26], the $\mathrm{SpO}_{2}$ TR in our NICU changed from $85-95 \%$ to $90-95 \%$ in November 2014. The ventilator used for respiratory support was the AVEA ventilator (Vyaire, Yorba Linda CA, United States) during the majority of the study period. In August 2015 the $\mathrm{CLiO}_{2}$ TM algorithm (Closed Loop of inspired Oxygen) [13] was implemented in the AVEA ventilator. This is a hybrid rule-based adaptive algorithm designed for $\mathrm{AOC}$ in preterm infants. In November 2018 the SLE6000 (SLE, London, United Kingdom) was introduced as standard of care ventilator. The SLE6000 has the VDL1.1 algorithm [27] built-in as the Oxygenie ${ }^{\circledR}$ option, a PID algorithm with several enhancements. Both algorithms are described in more detail elsewhere [28].

\section{Data analysis}

Data are presented as mean (SD), median (range), or number (percentage) as appropriate, with standard tests for normality. Statistical comparison was performed using an independent $t$ test, a Mann-Whitney U test, and a chi-square or Fisher's exact, respectively. Statistical analyses were performed by IBM SPSS Statistics for Mac, version 25 (IBM, Armonk, New York, USA). Two-tailed $P$ values of $<0.05$ were considered statistically significant. 
Table 1 Patient characteristics

\begin{tabular}{llll}
\hline Patient characteristics $N=588$ & Pre-AOC implementation $N=293$ & Post-AOC implementation $N=295$ & $P$ value* \\
\hline Gestational age in weeks, mean (SD) & $27.8(1.5)$ & $27.6(1.6)$ & $1035(260)$ \\
Birth weight in grams, mean (SD) & $1038(292)$ & $21(7.2)$ & 0.12 \\
Small for gestational age, n (\%) & $32(10.9)$ & $155(52.5)$ & 0.88 \\
Males, n (\%) & $165(56.3)$ & $255(87.3)$ & $157(53.2)$ \\
Antenatal corticosteroids, n (\%) & $250(86.2)$ & $99(33.5)$ & 0.15 \\
Caesarean delivery, n (\%) & $145(49.5)$ & $64(64.6)$ \\
Multiple pregnancy, n (\%) & $115(39.2)$ & $8(2.7)$ & 0.36 \\
of which monochorionic twins, n (\%) & $71(61.7)$ & $8(1-10)$ \\
Perinatal asphyxia, n (\%) & $4(1.4)$ & $8(2-10)$ & 0.37 \\
Apgar score at 5 min, median (range) & & 0.45 \\
\hline
\end{tabular}

*Statistical analysis with independent T-test, $\chi^{2}$, or nonparametric Mann-Whitney $U$ test as appropriate

\section{Results}

\section{Patient characteristics}

During the study period, 588 infants within the gestation range 24-29 weeks were admitted to the LUMC NICU, of which 8 were excluded from analysis (admitted $>24 \mathrm{~h}, n=6$; major congenital anomaly, $n=2$ ). In the pre-implementation cohort, 293 infants were included and compared with 295 infants in the post-implementation cohort. There were no significant differences in baseline characteristics between the groups (Table 1), so we can assume that treatment assignment cannot be retrospectively related to patient characteristics. The LUMC is a national referral centre for foetal therapy, which is reflected by a high number of multiple pregnancies in both groups.

\section{Clinical outcomes}

Mortality up until one month beyond full term corrected age was similar between groups (pre- vs. post-implementation: $30(10.2 \%)$ vs $32(10.8 \%) ; p=0.81$; Table 2$)$. There were no differences in morbidities between the groups, except that the incidence of culture proven sepsis in the post-implementation group was higher (96 (32.8\%) vs $121(41.0 \%) ; p=0.038)$. The length of stay in the NICU was not different between groups $(32.9 \pm 15.4$ vs $35.4 \pm$ $27.0 ; p=0.27)$.

Table 2 Clinical outcomes

\begin{tabular}{|c|c|c|c|}
\hline & $\begin{array}{l}\text { Pre-AOC } \\
\text { implementation }\end{array}$ & $\begin{array}{l}\text { Post-AOC } \\
\text { implementation }\end{array}$ & $\begin{array}{l}P \\
\text { value* }\end{array}$ \\
\hline Died, n (\%) & $30(10.2)$ & $32(10.8)$ & 0.81 \\
\hline Culture proven sepsis, n (\%) & $96(32.8)$ & $121(41.0)$ & 0.038 \\
\hline Necrotising enterocolitis (> stage $2 \mathrm{~A}), \mathrm{n}(\%)$ & $25(8.5)$ & $27(9.2)$ & 0.79 \\
\hline \multicolumn{4}{|l|}{ Retinopathy of prematurity } \\
\hline $\begin{array}{l}\text { none, }(\%) \\
\text { ETROP } 1 \text { (treatment indication), n }(\%)\end{array}$ & $\begin{array}{l}225(90.0) \\
16(6.4)\end{array}$ & $\begin{array}{l}226(90.0) \\
22(8.8)\end{array}$ & \multirow[t]{2}{*}{0.14} \\
\hline ETROP 2 (watchful waiting indication), n (\%) & $9(3.6)$ & $3(1.2)$ & \\
\hline Received laser coagulation, $\mathrm{n}(\%)$ & $13(5.2)$ & $14(5.6)$ & 0.84 \\
\hline Intraventricular haemorrhage ( $\geq$ stage 2$), \mathrm{n}(\%)$ & $55(18.8)$ & $50(16.9)$ & 0.56 \\
\hline Periventricular leukomalacia ( $\geq$ stage 2$), \mathrm{n}(\%)$ & $4(1.4)$ & $6(2.0)$ & 0.75 \\
\hline Days in NICU, mean (SD) & $32.1(25.6)$ & $35.1(27.2)$ & 0.18 \\
\hline \multicolumn{4}{|l|}{ Bronchopulmonary dysplasia } \\
\hline $\begin{array}{l}\text { Severe, } \mathrm{n}(\%) \\
\text { Moderate, } \mathrm{n}(\%)\end{array}$ & $\begin{array}{l}36(14.0) \\
12(4.7)\end{array}$ & $\begin{array}{l}48(18.6) \\
4(1.6)\end{array}$ & \multirow[t]{2}{*}{0.10} \\
\hline Mild, n (\%) & $45(17.4)$ & $38(14.7)$ & \\
\hline
\end{tabular}

Necrotising enterocolitis according to modified Bell staging criteria; ETROP, early treatment of retinopathy of prematurity; Intraventricular haemorrhage according to Papile's classification; Days on NICU until transfer to peripheral hospital or discharge; Bronchopulmonary dysplasia classification according to Dutch paediatric guidelines.

*Statistical analysis with independent T-test, $\chi^{2}$, Fisher's exact, or nonparametric Mann-Whitney U test as appropriate 
Table 3 Respiratory therapies

\begin{tabular}{llll}
\hline & $\begin{array}{l}\text { Pre-AOC } \\
\text { implementation }\end{array}$ & $\begin{array}{l}\text { Post-AOC } \\
\text { implementation }\end{array}$ & $\begin{array}{l}P \\
\text { value* }\end{array}$ \\
\hline High-frequency oscillation, n (\%) & $56(19.1)$ & $51(17.3)$ & 0.57 \\
Inhaled nitric oxide, $\mathrm{n}(\%)$ & $31(10.6)$ & $32(10.5)$ & 0.92 \\
Dexamethasone, $\mathrm{n}(\%)$ & $27(9.2)$ & $29(9.8)$ & 0.80 \\
Surfactant, n (\%) & $164(56.0)$ & $147(49.8)$ & 0.14 \\
Via intubation, n (\%) & $131(44.7)$ & $76(25.8)$ & $<0.001$ \\
Via minimally invasive technique, n (\%) & $33(11.3)$ & $71(24.1)$ & 0.029 \\
Invasive ventilation days, mean (SD) & $6.4(10.1)$ & $4.7(8.3)$ & 0.006 \\
CPAP days, mean (SD) & $10.8(11.7)$ & $13.9(15.2)$ & $<0.001$ \\
HFNC days, mean (SD) & $2.3(5.4)$ & $5.8(8.1)$ & 0.86 \\
Low flow days, mean (SD) & $1.5(3.4)$ & $1.5(3.2)$ & 0.008 \\
Supplemental oxygen days, mean (SD) & $8.0(13.5)$ & $11.3(16.9)$ & 0.58 \\
Average inspired oxygen & & & 0.93 \\
$\quad$ During first week, mean (SD) & $25.2(10.2)$ & $24.8(8.8)$ & $25.7(9.1)$ \\
During entire admittance, mean (SD) & $25.7(9.8)$ & & \\
\hline
\end{tabular}

CPAP continuous positive airway pressure, $H F N C$ high-flow nasal cannula; Average inspired oxygen (expressed as $\%$ ) while on respiratory support

*Statistical analysis with independent T-test or $\chi^{2}$ test as appropriate

\section{Respiratory therapy}

The use of a minimally invasive technique for surfactant administration was more prevalent in the post-implementation cohort (Table 3). In the post-implementation cohort, the duration of non-invasive mechanical support was longer (CPAP: $10.8 \pm 11.7$ vs $13.9 \pm 15.2$; HFNC: $2.3 \pm 5.4$ vs $5.8 \pm 8.1$ ), whereas the duration of invasive mechanical ventilation was shorter $(6.4 \pm 10.1$ vs $4.7 \pm 8.3)$. More supplemental oxygen was given in the post-implementation cohort $(8.0 \pm 13.5$ vs $11.3 \pm 16.9$ ). Otherwise both groups received similar respiratory therapy, including a similar average inspired oxygen while on respiratory support (first week: $25.2 \% \pm 10.2 \%$ vs $24.8 \% \pm 8.8 \%$; entire stay: $25.7 \% \pm 9.8$ vs $25.7 \% \pm 9.1$ ).

\section{Discussion}

In this retrospective study, we compared two large cohorts of preterm infants admitted to the NICU before and after implementation of AOC. Implementation led to no change in mortality and morbidities in preterm infants admitted to the NICU, despite a shift towards more non-invasive ventilation. The rates of mortality and morbidities were not very different from previous studies reporting short-term outcome in infants $<30$ weeks of gestation [1, 29]. Although we recently demonstrated that infants spent more time within TR after implementation of AOC, this does not seem to have had a clinically relevant impact in a large cohort.
This is the first study reporting on the effect of AOC on clinical outcome in preterm infants when this is implemented as standard of care. Several observational studies and clinical trials have demonstrated a beneficial effect of AOC on time spent within TR [11-18]. Although all authors speculated that this could affect clinical and neurodevelopmental outcome, these studies were not designed to demonstrate a difference in clinical outcome. To the best of our knowledge, there are no completed studies directly relating the achieved time within TR to clinical outcome. However, post-hoc analysis of the SUPPORT trial [7] demonstrated an increase in mortality for infants with a lower median $\mathrm{SpO}_{2}$; this could suggest that when $91-95 \%$ is considered the appropriate TR, more time under this range could lead to a lower median $\mathrm{SpO}_{2}$ and associated increase in mortality. Post-hoc analysis from the BOOST-II UK trial [30] also demonstrated that a lower achieved oxygen distribution was associated with an increase in NEC and mortality.

Using AOC in clinical practice could lead to a leftward shift of the $\mathrm{SpO}_{2}$ distribution. Bedside staff would seem to prefer to target higher $\mathrm{SpO}_{2}$ values within a prescribed range [31], whereas AOC devices for the most part target the middle $\mathrm{SpO} 2$ value of the TR, potentially leading to a lower median $\mathrm{SpO}_{2}$. A further consideration raised in regard to AOC implementation is that clinical deterioration may be masked, with possible adverse effects [32]. However none of the AOC trials have reported this, and our current findings showed no sign of this possible detrimental effect, with rates of mortality and morbidity similar between cohorts and in relation to previous studies [1, 29]. Indeed, it can be argued that continual 
assessment and display of the basal oxygen requirement as well as the number and magnitude of interventions by the AOC device could be used as an additional objective indicator of clinical deterioration. A large randomised controlled trial, the $\mathrm{FiO}_{2}-\mathrm{C}$ study [33], comparing AOC using any of the commercially available algorithms with manual titration, is currently being undertaken and will provide more data on the effect of AOC on clinical outcome.

The lack of effect of AOC on clinical outcome could be attributed to several causes. Some of the outcomes being assessed are relatively uncommon, and although we compared two large cohorts, effect sizes in outcome differences are likely to be small given the power in the study. Secondly, in our earlier study [15], the increased time in TR while using AOC was mainly attributable to a substantial decrease in $\mathrm{SpO}_{2}$ values above TR, whereas the time with $\mathrm{SpO}_{2}<80 \%$ was similar to manual titration. It could be that outcome is more largely influenced by the frequency and duration of hypoxia and hypoxic events [34] and by time above TR to a lesser extent. Finally, several changes to standard of care have been made during the study span which could have simultaneously influenced the outcome in either direction. For example, in November 2014, the lower limit of the TR was changed from 85 to $90 \%$ (likely narrowing the $\mathrm{SpO}_{2}$ distribution and shifting it to the right), and minimally invasive surfactant therapy was introduced. There may have been other factors we did not measure. A limitation of this study could be these unmeasured factors as they are not adjusted for.

It is conceivable and plausible that the introduction of AOC has contributed to a shift toward more non-invasive ventilation in our NICU. It may have contributed in two ways, firstly by rendering more stability to oxygenation and secondly by reducing the baseline oxygen requirement, as a direct consequence of continuous titration of $\mathrm{FiO}_{2}$ to target the midpoint of the $\mathrm{SpO}_{2}$ range. Although the retrospective nature of this study precludes the drawing of a definitive conclusion, the shift toward more non-invasive ventilation could prove promising. Prolonged mechanical ventilation is a risk factor for complications and has been directly associated with poor neurodevelopmental outcome [35]. In planned further studies, follow-up outcomes at 2 years will be compared between these cohorts.

Beyond its retrospective nature, another limitation of our study is that the actual time infants received AOC was not recorded. Local policy is to disable AOC once $\mathrm{SpO}_{2}$ values $>98 \%$ are recorded continuously for $30 \mathrm{~min}$ without supplemental oxygen, and thus it is possible that some infants only received AOC during a short period, diminishing any treatment effect. However, as we took the entire sample of patients admitted during the period of 2012-2018, the results are likely to be generalizable for NICUs in similar settings.

\section{Conclusion}

The implementation of AOC in a tertiary NICU had no significant effect on clinical outcomes at hospital discharge in this retrospective study of preterm infants but was associated with a shift toward more non-invasive ventilation.

Abbreviations AOC, Automated oxygen control(ler); BPD, Bronchopulmonary dysplasia; ETROP, Early Treatment of Retinopathy of Prematurity; $\mathrm{FiO}_{2}$, Fraction of inspiratory oxygen; IVH, Intraventricular haemorrhage; NEC, Necrotising enterocolitis; NICU, Neonatal intensive care unit; LUMC, Leiden University Medical Center; PID, Proportional-integral-derivative; PVL, Periventricular leukomalacia; ROP, Retinopathy of prematurity; $\mathrm{SpO}_{2}$, Oxygen saturation measured by pulse oximetry; TR, Target range; CPAP, Continuous positive airway pressure; HFNC, High-flow nasal cannula

Author's contributions H.H. Salverda was the principal author of the study and contributed to design of the study; performed clinical data collection, verification and analyses; and drafted the first version of the manuscript.

N.J. Oldenburger performed clinical data collection and analysis and drafted the first version of the manuscript. M. Rijken drafted the first version of the manuscript. S. Pauws performed data analyses and interpretation and drafted the first version of the manuscript. P.A. Dargaville contributed to the design of the study and drafted the first version of the manuscript. A.B. te Pas contributed to the design of the study and data interpretation and drafted the first version of the manuscript. All authors provided substantial intellectual contributions and approved the final version of the manuscript.

Availability of data and material Not available

Code availability Not applicable

\section{Disclosure}

Ethics approval The ethical board of the Leiden University Medical Center provided a statement of no objection for obtaining and publishing the anonymised data.

Consent to participate Not applicable

Consent for publication Not applicable

Conflict of interest AtP has received an unrestricted research grant from SLE Limited; they had no role in study design nor in the collection, analysis, and interpretation of data, writing of the report and decision to submit the paper for publication. The University of Tasmania and Royal Hobart Hospital have a patent concerning automated control of inspired oxygen concentration in the new-born infant and have a licensing agreement with SLE Limited in relation to OxyGenie automated oxygen control software.

Open Access This article is licensed under a Creative Commons Attribution 4.0 International License, which permits use, sharing, adaptation, distribution and reproduction in any medium or format, as long as you give appropriate credit to the original author(s) and the source, provide a link to the Creative Commons licence, and indicate if changes were made. The images or other third party material in this article are included in the article's Creative Commons licence, unless indicated otherwise in a 
credit line to the material. If material is not included in the article's Creative Commons licence and your intended use is not permitted by statutory regulation or exceeds the permitted use, you will need to obtain permission directly from the copyright holder. To view a copy of this licence, visit http://creativecommons.org/licenses/by/4.0/.

\section{References}

1. Rüegger C, Hegglin M, Adams M, Bucher HU, the Swiss Neonatal N (2012) Population based trends in mortality, morbidity and treatment for very preterm- and very low birth weight infants over 12 years. BMC Pediatr 12(1\%@ 1471-2431):17. https://doi.org/10. 1186/1471-2431-12-17

2. Hellström A, Hård AL (2019) Screening and novel therapies for retinopathy of prematurity - A review. Early Hum Dev 138:104846. https://doi.org/10.1016/j.earlhumdev.2019.104846

3. Hellstrom A, Perruzzi C, Ju M, Engstrom E, Hard AL, Liu JL, Albertsson-Wikland K, Carlsson B, Niklasson A, Sjodell L, LeRoith D, Senger DR, Smith LE (2001) Low IGF-I suppresses VEGF-survival signaling in retinal endothelial cells: direct correlation with clinical retinopathy of prematurity. Proc Natl Acad Sci U S A 98(10):5804-5808. https://doi.org/10.1073/pnas.101113998

4. Haynes RL, Folkerth RD, Keefe RJ, Sung I, Swzeda LI, Rosenberg PA, Volpe JJ, Kinney HC (2003) Nitrosative and oxidative injury to premyelinating oligodendrocytes in periventricular leukomalacia. $\mathrm{J}$ Neuropathol Exp Neurol 62(5):441-450. https://doi.org/10.1093/ jnen/62.5.441

5. Askie LM, Darlow BA, Finer N, Schmidt B, Stenson B, TarnowMordi W, Davis PG, Carlo WA, Brocklehurst P, Davies LC, Das A, Rich W, Gantz MG, Roberts RS, Whyte RK, Costantini L, Poets C, Asztalos E, Battin M, Halliday HL, Marlow N, Tin W, King A, Juszczak E, Morley CJ, Doyle LW, Gebski V, Hunter KE, Simes RJ (2018) Association between oxygen saturation targeting and death or disability in extremely preterm infants in the neonatal oxygenation prospective meta-analysis collaboration. JAMA 319(21):2190-2201. https://doi.org/10.1001/jama.2018.5725

6. van Zanten HA, Tan RNGB, van den Hoogen A, Lopriore E, te Pas $\mathrm{AB}$ (2015) Compliance in oxygen saturation targeting in preterm infants: a systematic review. Eur J Pediatr 174(12):1561-1572. https://doi.org/10.1007/s00431-015-2643-0

7. Network SSGotEKSNNR, Carlo WA, Finer NN, Walsh MC, Rich W, Gantz MG, Laptook AR, Yoder BA, Faix RG, Das A, Poole WK, Schibler K, Newman NS, Ambalavanan N, Frantz ID 3rd, Piazza AJ, Sánchez PJ, Morris BH, Laroia N, Phelps DL, Poindexter BB, Cotten CM, Van Meurs KP, Duara S, Narendran V, Sood BG, O'Shea TM, Bell EF, Ehrenkranz RA, Watterberg KL, Higgins RD (2010) Target ranges of oxygen saturation in extremely preterm infants. N Engl J Med 362(21):1959-1969. https://doi.org/ 10.1056/NEJMoa0911781

8. Schmidt B, Whyte RK, Asztalos EV, Moddemann D, Poets C, Rabi Y, Solimano A, Roberts RS, Canadian Oxygen Trial (COT) Group (2013) Effects of targeting higher vs lower arterial oxygen saturations on death or disability in extremely preterm infants: A randomized clinical trial. JAMA 309(20):2111-2120. https://doi.org/10. 1001/jama.2013.5555

9. Stenson BJT-MW, Darlow BA, Simes J, Juszczak E, Askie L, BOOST II United Kingdom Collaborative Group, BOOST II Australia Collaborative Group, BOOST II New Zealand Collaborative Group et al (2013) Oxygen saturation and outcomes in preterm infants. N Engl J Med 368(22):2094-2104

10. Fathabadi OS, Gale TJ, Olivier JC, Dargaville PA (2016) Automated control of inspired oxygen for preterm infants: What we have and what we need. Biomed Signal Process Control 28:9 18. https://doi.org/10.1016/j.bspc.2016.03.002

11. Claure N, Bancalari E, D'Ugard C, Nelin L, Stein M, Ramanathan R, Hernandez R, Donn SM, Becker M, Bachman T (2011) Multicenter crossover study of automated control of inspired oxygen in ventilated preterm infants. Pediatrics 127(1):e76-e83. https://doi.org/10.1542/peds.2010-0939

12. Claure N, D'Ugard C, Bancalari E (2009) Automated adjustment of inspired oxygen in preterm infants with frequent fluctuations in oxygenation: a pilot clinical trial. J Pediatr 155(5):640-645 e641642. https://doi.org/10.1016/j.jpeds.2009.04.057

13. Claure N, Gerhardt T, Everett R, Musante G, Herrera C, Bancalari E (2001) Closed-loop controlled inspired oxygen concentration for mechanically ventilated very low birth weight infants with frequent episodes of hypoxemia. Pediatrics 107(5):1120-1124. https://doi. org/10.1542/peds.107.5.1120

14. van Kaam AH, Hummler HD, Wilinska M, Swietlinski J, Lal MK, te Pas AB, Lista G, Gupta S, Fajardo CA, Onland W, Waitz M, Warakomska M, Cavigioli F, Bancalari E, Claure N, Bachman TE (2015) Automated versus manual oxygen control with different saturation targets and modes of respiratory support in preterm infants. J Pediatr 167(3):545-550 e541-542. https://doi.org/10.1016/ j.jpeds.2015.06.012

15. Van Zanten HA, Kuypers KLAM, Stenson BJ, Bachman TE, Pauws SC, te Pas AB (2017) The effect of implementing an automated oxygen control on oxygen saturation in preterm infants. Arch Dis Child Fetal Neonatal Ed 102(5):F395-F399. https://doi.org/10. 1136/archdischild-2016-312172

16. Waitz M, Schmid MB, Fuchs H, Mendler MR, Dreyhaupt J, Hummler HD (2015) Effects of automated adjustment of the inspired oxygen on fluctuations of arterial and regional cerebral tissue oxygenation in preterm infants with frequent desaturations. J Pediatr 166(2):240-244 e241. https://doi.org/10.1016/j.jpeds. 2014.10.007

17. Lal M, Tin W, Sinha S (2015) Automated control of inspired oxygen in ventilated preterm infants: crossover physiological study. Acta Paediatr 104(11):1084-1089. https://doi.org/10.1111/apa. 13137

18. Plottier GK, Wheeler KI, Ali SK, Fathabadi OS, Jayakar R, Gale TJ, Dargaville PA (2017) Clinical evaluation of a novel adaptive algorithm for automated control of oxygen therapy in preterm infants on non-invasive respiratory support. Arch Dis Child Fetal Neonatal Ed 102(1):F37-F43. https://doi.org/10.1136/ archdischild-2016-310647

19. (2003) Revised indications for the treatment of retinopathy of prematurity: results of the early treatment for retinopathy of prematurity randomized trial. Arch Ophthalmol 121(12):1684-1694. https://doi.org/10.1001/archopht.121.12.1684

20. Good WV (2006) The Early Treatment for Retinopathy Of Prematurity Study: structural findings at age 2 years. Br J Ophthalmol 90(11):1378-1382. https://doi.org/10.1136/bjo.2006. 098582

21. Jobe AH, Bancalari E (2001) Bronchopulmonary dysplasia. Am J Respir Crit Care Med 163(7):1723-1729. https://doi.org/10.1164/ ajrccm.163.7.2011060

22. Kliegman RM, Walsh MC (1987) Neonatal necrotizing enterocolitis: pathogenesis, classification, and spectrum of illness. Curr Probl Pediatr 17(4):213-288. https://doi.org/10.1016/0045-9380(87) 90031-4

23. Papile LA, Burstein J, Burstein R, Koffler H (1978) Incidence and evolution of subependymal and intraventricular hemorrhage: a study of infants with birth weights less than $1,500 \mathrm{gm}$. J Pediatr 92(4):529-534. https://doi.org/10.1016/s0022-3476(78)80282-0

24. Volpe JJ (1989) Intraventricular hemorrhage and brain injury in the premature infant. Diagnosis, prognosis, and prevention. Clin Perinatol 16(2):387-411 
25. de Vries LS, Eken P, Dubowitz LM (1992) The spectrum of leukomalacia using cranial ultrasound. Behav Brain Res 49(1):16. https://doi.org/10.1016/s0166-4328(05)80189-5

26. Sweet DG, Carnielli V, Greisen G, Hallman M, Ozek E, Te Pas A, Plavka R, Roehr CC, Saugstad OD, Simeoni U, Speer CP, Vento M, Visser GHA, Halliday HL (2019) European Consensus Guidelines on the Management of Respiratory Distress Syndrome - 2019 Update. Neonatology 115(4):432-450. https://doi.org/10. $1159 / 000499361$

27. Dargaville PA, Sadeghi Fathabadi O, Plottier GK, Lim K, Wheeler KI, Jayakar R, Gale TJ (2017) Development and preclinical testing of an adaptive algorithm for automated control of inspired oxygen in the preterm infant. Arch Dis Child Fetal Neonatal Ed 102(1): F31-f36. https://doi.org/10.1136/archdischild-2016-310650

28. Salverda HH, Cramer SJE, Witlox R, Dargaville PA, Te Pas AB (2020) Automated oxygen control in preterm infants, how does it work and what to expect: a narrative review. Arch Dis Child Fetal Neonatal Ed:fetalneonatal-2020-318918. https://doi.org/10.1136/ archdischild-2020-318918

29. Glass HC, Costarino AT, Stayer SA, Brett CM, Cladis F, Davis PJ (2015) Outcomes for extremely premature infants. Anesth Analg 120(6):1337-1351. https://doi.org/10.1213/ane.0000000000000705

30. Stenson BJ (2019) Achieved oxygenation saturations and outcome in extremely preterm infants. Clin Perinatol 46(3):601-610. https:// doi.org/10.1016/j.clp.2019.05.011
31. Hagadorn JI, Furey AM, Nghiem TH, Schmid CH, Phelps DL, Pillers DA, Cole CH, Group AVS (2006) Achieved versus intended pulse oximeter saturation in infants born less than 28 weeks' gestation: the AVIOx study. Pediatrics 118(4):1574-1582. https://doi. org/10.1542/peds.2005-0413

32. Claure N, Bancalari E (2009) Automated respiratory support in newborn infants. Semin Fetal Neonatal Med 14(1):35-41. https:// doi.org/10.1016/j.siny.2008.08.008

33. University Hospital T (2018) Effects of Closed-loop Automatic Control of FiO2 in Extremely Preterm Infants. https:// ClinicalTrials.gov/show/NCT03168516

34. Martin RJ, Wang K, Koroglu O, Di Fiore J, Kc P (2011) Intermittent hypoxic episodes in preterm infants: do they matter? Neonatology 100(3):303-310. https://doi.org/10.1159/000329922

35. Vliegenthart RJS, van Kaam AH, Aarnoudse-Moens CSH, van Wassenaer AG, Onland W (2019) Duration of mechanical ventilation and neurodevelopment in preterm infants. Arch Dis Child Fetal Neonatal Ed 104(6):F631-f635. https://doi.org/10.1136/ archdischild-2018-315993

Publisher's Note Springer Nature remains neutral with regard to jurisdictional claims in published maps and institutional affiliations. 